\title{
INSURANCE TENDER SELECTION USING MULTIPLE CRITERIA DECISION MAKING
}

\author{
Poshitha Ratnayake* \\ School of Computing \\ Asia Pacific Institute of Information Technology \\ Colombo, Sri Lanka \\ E-mail: poshitha.ratnayake@yahoo.com \\ Eranjan Padumadasa \\ Queen Mary, University of London \\ London, United Kingdom \\ E-mail: e.u.padumadasa@qmul.ac.uk
}

\begin{abstract}
Introduction: This paper involves assessing the most suitable insurance company for company $\mathrm{X}^{1}$ using Multiple Criteria Decision Making (MCDM). This company is one of the biggest financial organizations and problems were identified with the existing process of insurance tender selection. The manual nature of the current process is very tedious and takes almost three months to complete and this increases the probability of error and also leads to employee dissatisfaction.
\end{abstract}

Artifact: To provide a solution to this problem, several MCDM models including Analytical Hierarchy Process (AHP), Analytical Network Process (ANP), and Technique for Order Preference by Similarity to the Ideal Solution (TOPSIS) and Fuzzy Sets were researched to determine the best MCDM model for this scenario.

After conducting a thorough research it was concluded that the best approach would be to use a hybrid methodology that combines AHP and TOPSIS. By using AHP to calculate the weights and using TOPSIS to determine the best alternative, accurate results can be obtained, as it combines the strengths of the two methodologies. In terms of time and complexity also this hybrid methodology doesn't involve a high level of complexity as in ANP and also with regard to the time factor, although the calculation of weights may require some time, using TOPSIS the best alternative can be determined relatively fast.

Methodology: To validate and verify the quality and to ensure that the system worked as intended, several testing strategies such as User Acceptance testing and Accuracy testing was used. The samples used for these testing methods were the staff of the insurance department in company $\mathrm{X}$.

\footnotetext{
* Corresponding author

${ }^{1}$ The name of the company cannot be disclosed due to a non-disclosure agreement between the researchers and the organization.
} 
Results: The results of the user acceptance testing showed an over $70 \%$ satisfaction with the system. The system had been greatly improved in terms of the time taken as well as the efficiency and accuracy of the decision.

Two cases were taken for the accuracy testing and in both cases the manual calculation and system calculation matched except for slight differences to the decimal point. However the overall results were the same. This showed that the model worked successfully in determining the best insurance tender.

Conclusion: AHP-TOPSIS could be combined to form a more effective model that combines the strengths of each model to reduce its limitations in order to select the best insurance tender. By using this model the throughput efficiency of the evaluation process was increased to $70 \%$ and the time taken to complete the overall process was reduced to at least a month.

Keywords: Insurance, MCDM, AHP, TOPSIS

\section{Introduction}

Insurance is an important concept especially for financial organizations as all the risks must be fully insured in order to avoid loss. Insurance is a measure of risk transfer and finding the right insurer is an important decision that would not only cover the potential risks to the organization but also find the insurer with the best premium.

The decision to which insurance company to select is important and it is based on several criteria. These criteria including market position, quick service and professional capability, many of which are hard to compare and quantify and therefore can be regarded as a MCDM problem.

Company $\mathrm{X}$ was investigated and it was found that there were some drawbacks in the selection of insurance tenders. It was identified that there was a problem in the accuracy of decision making. In the past years some of the selected insurance companies did not pay the claims and rejected claims which were under the agreement.

With the current advancement of technology it is possible to make use of IT solutions in order to facilitate the decision making process and provide more accurate results. In order to provide a solution to this problem, research was conducted into several MCDM methods to determine the best method to solve this problem.

\section{Problem Statement}

"How to improve the insurance tender procedure as the manual nature of the existing tender procedure system is very tedious and time consuming thereby increasing the probability of error and also leading to employee disatisfaction" 


\section{Literature Review}

The methodology selected is a hybrid methodology, AHP - TOPSIS, combining both TOPSIS and AHP. Four types of MCDM methods were evaluated and applied to the scenario of this project. Based on the evaluation conducted, it was identified that the MCDM methods such as AHP, ANP, TOPSIS and Fuzzy sets can be used in this context; however the degree of effectiveness in addressing the problem does vary.

According to Kinoshita (2005), AHP is very effective in the decision making process as it ensures procedural rationality. Kinoshita (2005) also states that AHP is very similar to the human behavior in decision making and also the pairwise comparison conducted ensures that all possibilities are explored so that the best results can be provided. Chen (2005) also supports Kinoshita (2005) stating that AHP is a decision making approach that is easy to understand and implement. According to Chen (2005), AHP considers both qualitative and quantitative aspects, structures the problem and provides the best alternative depending on the criteria. Forman and Gass (2001) add that AHP provides a way to simplify the complexity of a problem.

Chen (2005) further states that AHP has been extensively implemented in problems where many criteria need to be evaluated in order to find the best alternative. Korhonen and Voutilainen (2006) stated that AHP is a widely known and used standard for solving MCDM problems and that it has the ability to consider both subjective and judgmental information. AHP's use in a similar scenario to this project, where AHP was used in finding the most preferred alliance structure between banks and insurance companies, proved to be very successful according to Korhonen and Voutilainen (2006).

Forman and Gass (2001) while stating that AHP is probably the most widely used decision making approach they say that AHP is rarely used by itself for solving MCDM problems; it is used in conjunction with other methods. Helper and Mazur (2007) state that despite a few limitations AHP is an effective and accurate method of finding the relative importance of each of the needs in the hierarchy; it captures all the necessary criteria and thoroughly evaluates them in an understandable and simple manner.

After considering these factors it was decided that implementing AHP would be of great use in solving this problem, however only AHP would not be sufficient, however since it is an effective and accurate method and it was said by authors that AHP was used in combination with other models it was decided to implement a hybrid method involving AHP.

According to Percin (2010), although ANP may be a simple, easy to use and flexible approach it involves a very complex procedure that requires a lot more calculations compared to AHP and thus demands more effort. He also states that due to this complexity and time consuming nature there are only a few applications of ANP.

However, in contrast to AHP, ANP considers the dependency among the criteria and alternatives thereby giving more accurate results (Percin, 2010). According to Poonikom, O'Brien and Chansa-ngavej (2004), ANP has the ability to incorporate economic, cost and risk factors in its evaluation and although it may be a very complex process it helps to capture the complexity of the real world.

Considering all these factors and due to the complexity and time consuming nature of ANP, it was decided that ANP would not be necessary to solve this problem. As said by several authors, it is not 
necessary to use complex methodologies to solve problems when it can be done in a simpler manner thus saving the time and effort.

According to Olsen (2004), TOPSIS requires only limited subjective input compared to some of the other MCDM methods and it can also identify the best alternative very quickly. He further stated that in certain situations TOPSIS performed better than AHP, however when the number of criteria increased TOPSIS performed less accurately than AHP. Olsen (2004) further stated that in order to obtain accurate results in TOPSIS accurate weights must be obtained.

As stated by Markovic (2010), TOPSIS is a very useful method for solving MCDM problems and it isn't very complex compared to the other MCDM methods. Hao and Qing-sheng (2006) also state that the evaluation in TOPSIS is scientific, accurate and practical. However according to Aghajani and HadiVencheh (2011), even though TOPSIS identifies the best alternative as the alternative that is closest to the positive ideal solution and farthest from the negative ideal solution, this is not always the case, meaning that the alternative closest to the positive ideal solution is not exactly the furthest from the negative ideal solution.

Taking into consideration these factors, TOPSIS seems to be an effective method in solving MCDM problems, however although limited, there is still subjective information used which may bias the results.

According to Chen (2005), fuzzy sets were introduced due to the inability to clearly identify the weights of the criteria and alternatives involved. As stated by the Department for Communities and Local Government (2009), fuzzy sets capture the inconsistency of our natural language in discussing the problems and it attempts to capture these and quantify them using membership functions.

However Saaty (2007c) states that people use fuzzy sets when it is known that it has been ranked the worst of the methods available. Buede and Maxwell (1995) as cited by Saaty (2007c) have also stated that AHP is a consistent technique whereas fuzzy is the least consistent. Beheshti \& Lollar (2008) stated that the fuzzy set theory hasn't been widely implemented in management aspects. Ordoobadi (2009), further stated that the application of fuzzy sets alone many not provide accurate results.

Taking into consideration these factors, it was decided that implementing fuzzy sets was not suitable for this project.

After evaluating all the above discussed methodologies and taking into consideration several factors such as time and complexity etc... it was decided to go ahead with a hybrid methodology AHP - TOPSIS combining both AHP and TOPSIS to bring about a more effective model.

The reason for this integration was because in TOPSIS, it is argued by several authors that the subjective input received can bias the results obtained as the weights of the criteria and ratings of alternatives are both obtained through judgment as shown in the application of TOPSIS earlier.

However in AHP, although the traditional AHP method may be subjective, using Ishizaka's method the results are much more accurate. Ishizaka proposed using the transitivity rule in pairwise comparisons thus further reducing the amount of subjective input received. This advantage of AHP can be integrated into TOPSIS to reduce or eliminate its disadvantage. 
The method of TOPSIS where the best alternative is selected depending on its distance from the positive and negative ideal solution has been praised by many stating that it is a very effective method and produces accurate results. Also many have said that it follows the human rationale in using this approach thereby making it easier to understand and practice.

So by using AHP to calculate the weights and using TOPSIS to determine the best alternative, accurate results can be obtained, as it is combining the strengths of the two methodologies. In terms of time and complexity also this hybrid methodology doesn't involve a high level of complexity as in ANP and also with regard to the time factor, although the calculation of weights may require some time, using TOPSIS the best alternative can be determined relatively fast.

\section{Artefact}

The proposed system is a client server application. The reason for implementing a client server application is so that the system can be extended to the insurance companies and the company branches in order for them to submit quotations and the finance information respectively, whilst the standalone system is used by the employees of company X.

The proposed solution is as follows:

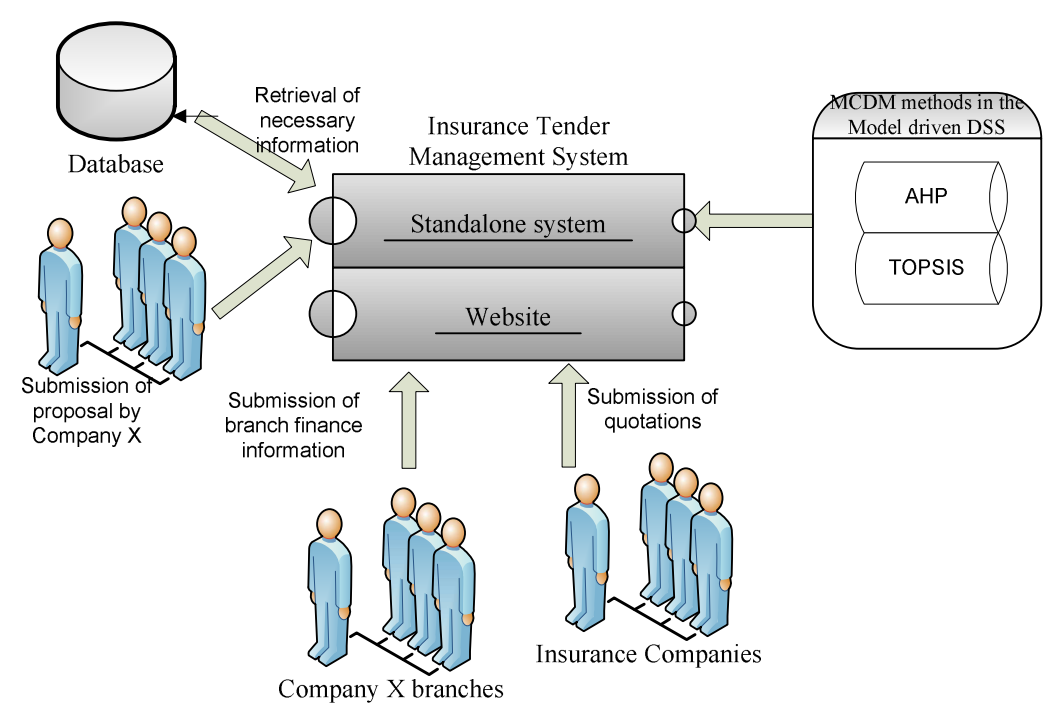

Figure 1: Solution Architecture

The users of the system are the insurance companies, the branches of Company $\mathrm{X}$ and also the Staff of Company X. The figure above depicts some of the reasons why these users need access to the system.

In the proposed solution, AHP is used to calculate the weights and TOPSIS is used to rank the alternatives in order to determine the most suitable insurance company. The database is used to store all the information regarding the processes involved including login details and quotation details. 


\section{Methodology}

According to Nidhra and Dondeti (2012), the main purpose of testing is to validate and verify the quality of the solution developed and is done with the intention of breaking the system (i.e. with the intention of finding bugs). Therefore testing is conducted on the developed solution to validate and verify the quality and to ensure that the system works as intended. After researching many testing methods it was decided to go ahead with the Unit Testing, Integration Testing, System Testing, User Acceptance Testing and Accuracy Testing.

Shelly and Rosenblatt (2012) mentioned that the goal of unit testing is to identify and fix any errors that may cause the system to unexpectedly crash and any errors in the code logic. Therefore the entire system will be tested unit by unit to ensure that it runs as intended. According to Anderson (2011), integration testing refers to testing where components are combined together and tested to ensure smooth running between the integrated components. System testing involves testing the entire developed solution and ensures that the system has the required functionalities (Shelly \& Rosenblatt, 2012). User Acceptance testing involves allowing the users or stakeholders of the system to test the system and allows the users to decide if the requirements have been met from their perspective and in their environment (Atkins, 2009). Accuracy testing is performed for the model, in this case for AHP-TOPSIS, to ensure that the model works accurately.

\section{Results}

On the first iteration of unit testing and integration testing, defects were encountered, therefore a second iteration was run for each of those testing methods after the defects were corrected and it ran smoothly. System testing was also conducted successfully.

User acceptance testing was conducted using a questionnaire after having the user's experience the system. The feedback received differed comparatively but it can be summarized as follows:

For the standalone system:

\begin{tabular}{|c|cccc|}
\hline $80 \%$ & $74 \%$ & $75 \%$ & $78 \%$ & $78 \%$ \\
$70 \%$ & & & \\
\cline { 2 - 5 } & JEO & Clerk & Clerk & Senior Manager \\
& & Overall Feedback & \\
\hline
\end{tabular}

Figure 2: Feedback for standalone system 
For the website:

\begin{tabular}{|l|c|c|}
\hline $75 \%$ & $71 \%$ & $74 \%$ \\
$70 \%$ & & \\
$65 \%$ & & Branch \\
\cline { 2 - 3 } & Insurance company & \\
& & घOverall feedback \\
& & \\
& &
\end{tabular}

Figure 3: Feedback for website

Accuracy testing was conducted on the model used - AHP TOPSIS. First it was conducted using real values from company $\mathrm{X}$, where the manual decision result was compared with the result from the system. Information on the selected insurance companies for the past ten years as well as the other insurance companies considered was obtained from company X. The results showed 5/10 differences, however in those cases, it was identified that the selected insurance company (from the manual decision) was unable to perform as expected, whereas, the system selected a more capable insurance company.

Secondly, two cases were taken, one case where the CR was less than 0.1 and another case where the CR was more than 0.1 . The manual calculation was compared with the system calculation. In both cases the manual calculation and system calculation matched except for slight differences to the decimal point. However the overall results were the same.

\section{Conclusion}

Decision making is not an easy task especially in this scenario where the current system operates in a manual environment thus giving rise to many problems such as employee dissatisfaction and low efficiency. In addition to this if the appropriate insurance company is not selected it poses a huge risk to the company as it could incur severe losses in case of any incidents.

MCDM methodologies were investigated in order to determine the best method possible to implement in the proposed system. The MCDM models considered included AHP, ANP, TOPSIS and Fuzzy sets. Each of these models were deeply investigated and also applied to this scenario to assess each model's suitability. The results of this research and application showed that each model had its own advantages and disadvantages. When considering AHP it provided a very simple and humanly solution to the problem and also with its use of the pairwise comparison matrix explored all possible aspects in order to provide the best result, however many criticized AHP for its tediousness as the criteria involved increased and also due to it being entirely subjected to the users input. When considering ANP, although it improved on certain limitations of AHP, it involved a high level of complexity and was time consuming. Many authors also stated that ANP is mostly used when AHP cannot be applied. However AHP was applicable and therefore it was decided not to go into the complexities of ANP. TOPSIS was praised by many authors for its method of selecting the best alternative by calculating the distances to the positive and negative ideal situations; however it was criticized for its calculation of weights. Fuzzy sets were criticized by some authors as the worst of the methods available, whilst some authors acknowledged its method. In the application of fuzzy however it was found that it was entirely based on judgment and the 
degree of subjectivity was high and therefore not considered as part of the solution. After evaluating all the considered models it was decided to go ahead with a hybrid model - AHP TOPSIS as both these models could be combined to form a more effective model.

However several limitations were also identified with regard to the model chosen. Although AHP TOPSIS provided an effective solution to the problem at hand, the transitivity rule applied to AHP in calculating the weights has certain flaws as were seen during the testing stage. The transitivity rule is used in AHP to reduce the number of user inputs in the pairwise comparison matrix thus reducing the level of subjectivity. The scale used in AHP ranges from 1 to 9 and 1/2 to 1/9 but when the transitivity principle is applied, when the user inputs large values from the scale, the transitivity results in producing values out of the scale in the pairwise matrix. These values then have no meaning according to the scale. Although this limitation does not affect the project at hand largely it is still a risk and a limitation of the identified solution. Another limitation identified was that the desired values in TOPSIS were based on expert judgment as the organization wished to have a bit more control in the process. A future enhancement could be to look into fuzzy sets to come up with the desired values.

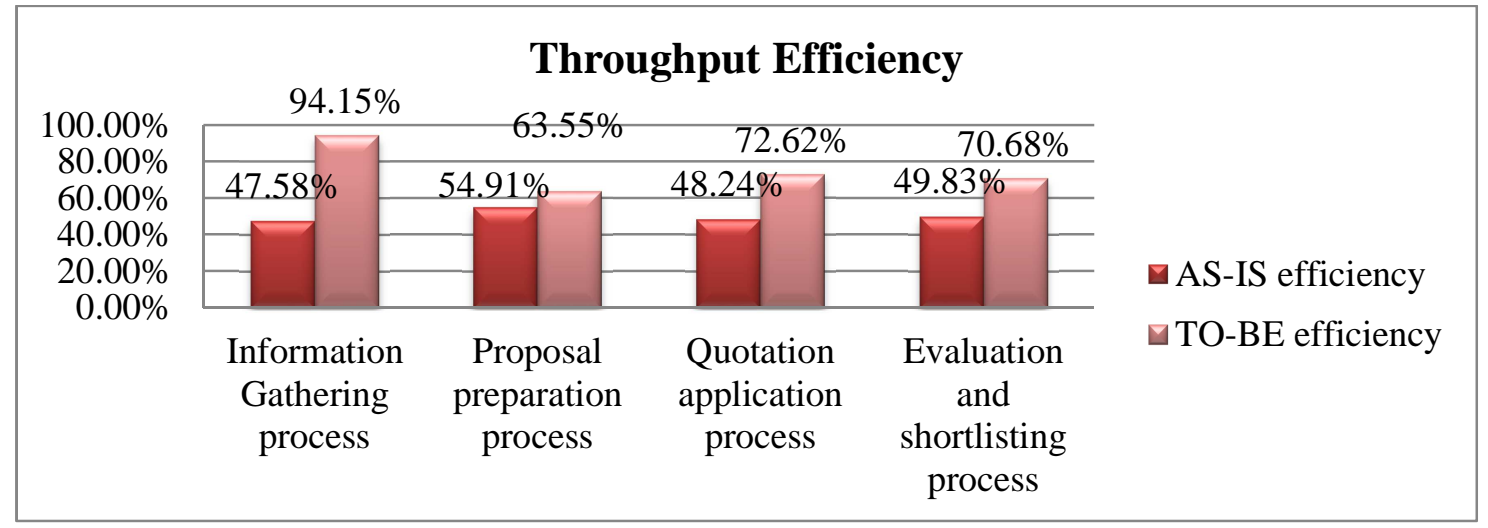

Figure 4: Throughput Efficiency

By using this model the throughput efficiency of the evaluation process was increased to $70 \%$ and the time taken to complete the overall process was reduced to at least a month. Also the AS-IS and TO-BE comparison showed a great increase in the overall efficiency of the processes. As shown in figure 4, all the processes showed efficiencies well above $50 \%$ and had undergone significant improvement compared to the AS-IS processes.

\section{References}

Aghajani, M., Hadi-Vencheh, A. (2011). A multiple attribute decision making model in the presence of grey numbers. [Online]. Available from: http://www.ipedr.com/vol19/13-ICAMS2011-A00026.pdf

Anderson, S. (2011). Integration testing. [Online]. Available from: http://www.inf.ed.ac.uk/teaching/courses/st/2011-12/Resource-folder/10_integration.pdf. 
P. Ratnayake, E. Padumadasa/ Insurance Tender Selection using Multiple Criteria Decision Making

Atkins, T. (2009). User Acceptance Testing. [Online]. Available from: http://www.silverpath.com/resources/Silverpath-UserAcceptanceTestingWhitepaper-090203.pdf

Chen, M. F. (2005). Using FAHP to evaluate non store retailing channel alternatives. ISAHP. July 2005. Honolulu.

Department for Communities and Local Government. (2009). Multi-criteria analysis: a manual. [Online]. Available from: http://eprints.lse.ac.uk/12761/1/Multi-criteria_Analysis.pdf

Forman, E., Gass, S. (2001). The Analytic Hierarchy Process - An Exposition. [Online]. Available from: http://www.johnsaunders.com/papers/ahpexpo.pdf

Hao, L., Qing-sheng, X. (2006). Application of TOPSIS in the bidding evaluation of manufacturing enterprises. [Online]. Available from: http://210.40.3.63/paper/200610.pdf

Hepler, C., Mazur, G. (2007). The Analytic Hierarchy Process. [Online]. Available from: http://www.mazur.net/works/Hepler_Mazur_2007_AHP_with_Customers_and_Management.pdf

Kinoshita, E. (2005). Why we need AHP/ANP instead of Utility theory in today's complex world: AHP from the perspective of bounded rationality. ISAHP. July 2005. Honolulu.

Korhonen, P., Voutilainen, R. (2006). Finding the most preferred alliance structure between banks and insurance companies. European Journal of Operational Research. 175, p. 1285-1299.

Markovic, Z. (2010). Modification of TOPSIS method for solving of multi-criteria tasks. Yugoslav Journal of Operations Research. 20, p.117-143.

Nidhra, S. Dondeti J. (2012). Black box and white box testing techniques - A literature review. [Online]. Available from: http://airccse.org/journal/ijesa/papers/2212ijesa04.pdf

Olsen. D. L. (2004). Comparison of Weights in TOPSIS Models. Mathematical and Computer Modelling. p. 1-7

Percin, S. (2010). Use of analytic network process in selecting knowledge management strategies. Management Research Review. 33 (5). 
Poonikom, K., O'Brien, C., Chansa-ngavej, C. (2004). An application of the Analytic Network Process (ANP) for university selection decisions. ScienceAsia. 30, p. 317-326.

Saaty, T. L. (2007c). The Analytic Network Process. [Online]. Available from: http://www.sid.ir/en/vewssid/j_pdf/115720080101.pdf

Shelly, G.B. and Rosenblatt, H. J. (2012). System Analysis and Design. 9th ed. Boston: Course Technology

Beheshti, H. M., Lollar, J. G. (2008). Fuzzy logic and performance evaluation: discussion and application. International Journal of Productivity and Performance Management. 57, p.237-246.

Ordoobadi, S. M. (2009). Development of a supplier selection model using fuzzy logic. Supply Chain Management: An International Journal. 14, p.314-327. 